\title{
Fast Switching Planar Power Module With SiC MOSFETs and Ultra-low Parasitic Inductance
}

\author{
Arash Edvin Risseh ${ }^{1 *}$, Hans-Peter Nee ${ }^{1}$, Konstantin Kostov ${ }^{2}$ \\ 1 School of Electrical Engineering, KTH Royal Institute of Technology, Stockholm, Sweden \\ 2 The Mads Clausen Institute, SDU Electrical Engineering, Sonderborg, Denmark \\ *E-mail: risseh@kth.se
}

\begin{abstract}
Parasitic inductances caused by the package of semiconductor devices in power converters, are limiting the switching speed and giving rise to higher switching losses than necessary. In this study a half-bridge planar power module with Silicon Carbide (SiC) MOSFET bare dies was designed and manufactured for ultra-low parasitic inductance. The circuit structure was simulated and the parasitic inductances were extracted from ANSYS-Q3D. The values were then fed into LT-Spice to simulate the electrical behavior of the half-bridge. The experimental and simulation results were compared to each other and were used to adjust and easily extend the simulation model with additional MOSFETs for higher current capability. It was shown that the proposed planar module, with four parallel SiC MOSFETs at each position, is able to switch $600 \mathrm{~V}$ and $400 \mathrm{~A}$ during 40 and $17 \mathrm{~ns}$ with $\mathrm{E}_{\mathrm{ON}}$ and $\mathrm{E}_{\mathrm{OFF}}$ equal to 3.1 and $1.3 \mathrm{~mJ}$, respectively. Moreover, unlike the commercial modules, this design allows double-sided cooling to extract the generated heat from the device, resulting in lower operating temperature.
\end{abstract}

\section{INTRODUCTION}

Efforts have been put into development of fast switching speed in power electronics [1]-[3]. Among others, this may be done by adding different components to the circuit, proposing turn-on/off strategies [4], [5], suggesting gate-driver circuits [6], [7], or by using new device- and package-structures [8], [9]. The fundamental issue regarding switching time in power semiconductor devices is the parasitic inductance of the circuit board and the package of the device itself. The parasitic inductance increases the rise- and fall times, which in turn increase the switching losses and also limit the switching frequency. Furthermore, the inductance together with the capacitance in the circuit cause overshoots and oscillations which also give rise to additional losses and thereby higher junction temperature and accelerated component aging. The impact of the parasitic inductance in power converters as well as new packages and in power modules, with low parasitic inductance, has earlier been studied [10]-[15].

Silicon Carbide (SiC) metal-oxide semiconductor field-effect transistors (MOSFETs) have been developed rapidly during the last decade. SiC MOSFETs have magnificent characteristics such as low input capacitance, very low $\mathrm{ON}$-state resistance and capability of operation at high temperature and frequency. However, the commercially available $\mathrm{SiC}$ MOSFET modules are packaged using technology developed for silicon insulated gate bipolar transistors (IGBTs) featuring only single-side cooling and high parasitic inductance. In order to extensively take advantage of $\mathrm{SiC}$ MOSFETs, new double-side cooled packages with ultra-low inductance are required. In order to eliminate the parasitic inductances, the regular package of the device may completely be excluded.

In this investigation, a planar power module with four SiC MOSFET bare dies, directly connected to two printed circuit boards (PCBs), was designed and manufactured. The power module was formed as a half-bridge where two chips were placed in parallel at each position, and the upper and lower switches were connected to two separate gate drivers. Wolfspeed's CPM2-1200-0025B (1.2 kV \& 98 A \& $25 \mathrm{~m} \Omega$ ) bar dies were used as SiC MOSFETs in the module. When the functionality of the module was verified the module was exposed to a double-pulse test (DPT). Later on, the measurement results were used to refine and obtain an accurate model of the structure. The new simulation model was then used to expand the module with additional bare dies to increase the current capacity. The manufactured module, as well as the expanded model has extremely low parasitic inductances which enables fast switching speed and low losses. A similar concept was reported in an earlier study where a module was set up as a DC/DC converter with low voltage and current(15 V \& $1 \mathrm{~A})$ [16]. The outline of this study is as follows. In Section II the structure and the test procedure of the module as well as the experimental results are presented. The parasitic components of the structure were simulated in LT-Spice and the results are presented in Section III followed by a presentation of the proposed planar module, extended with four chips in Section IV. Section V presents the results showing the waveforms and switching times of the proposed extended module. Finally, in Section VI conclusions are drawn.

\section{CONCEPT AND MEASUREMENTS}

The package of a MOSFET and interconnections to its substrate create internal and external parasitic elements such as inductances and capacitances. Figure 1 shows a model of a power MOSFET where internal parasitic elements due to the package of the device, and external parasitic elements due to the outside circuits, are shown. In order to reduce the parasitic inductances, the chip (bare die) of the MOSFET may directly be attached to a substrate where other components such as gate-drive circuits operate. By excluding the wire-bonds and leads of the package, the total parasitic elements will be reduced. 


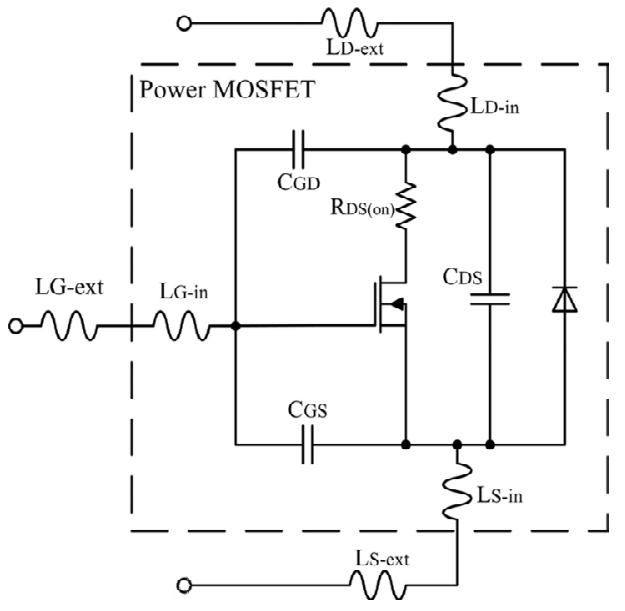

Fig. 1. Model of a power MOSFET including parasitic elements. The internal elements are caused by the package of the device and the external elements are created by the external circuit.

A half-bridge module as seen in Fig. 2 was considered in this study. It consists of four MOSFETs, two parallel are placed at the upper- and two parallel are at the lower positions, respectively. SiC MOSFETs bare dies from Wolfspeed (CPM2-1200-0025B) were employed in this design. The structure, the size of the bare die pads, and the type of the substrate (FR4) were drawn in a simulation software (ANSYS Q3D) to determine the parasitic elements of the module. Part of the simulated structure as well as the size and the layout of the bare die are shown in Fig. 3. The dies were placed and sandwiched between two PCBs to create connections between the two sides of the dies, as shown in Fig. 4. PCB 1 is the main substrate where the gate-drive circuits and other necessary components are placed. The connections to the Drain pads are also placed on PCB 1 . The purpose of PCB 2 is to create connections to the Source and Gate pads and thereby connect them to PCB 1 via connectors, see Figs. 3 and 5 . The entire manufacturing procedure and more details regarding the structure is described in [17]. The parasitic elements could be determined and extracted from ANSYS Q3D. The values are listed in Tables I and II which confirm that the structure exhibits extremely low inductances. According to the simulations, the parasitic inductance $\left(\mathrm{L}_{\text {stray }}\right)$ of the module is approximately $0.659 \mathrm{nH}$ which is approximately $96 \%$ lower than most commercial $1.2 \mathrm{kV}$ half-bridge modules.

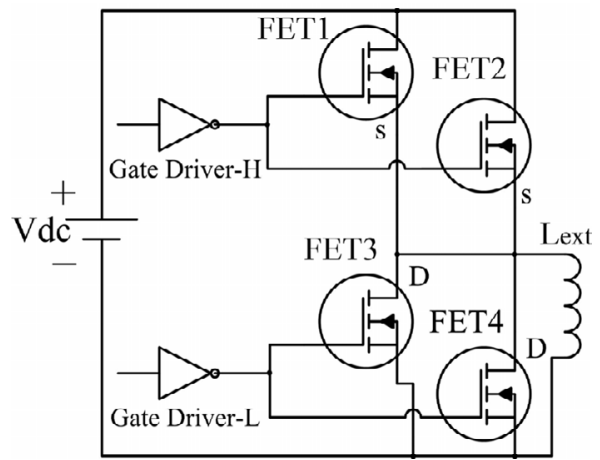

Fig. 2. Schematic diagram of the half-bridge configuration with two SiC MOSFETs in parallel at each position. An external inductor $\left(\mathrm{L}_{\mathrm{ext}}\right)$ was employed to perform double double pulse test.

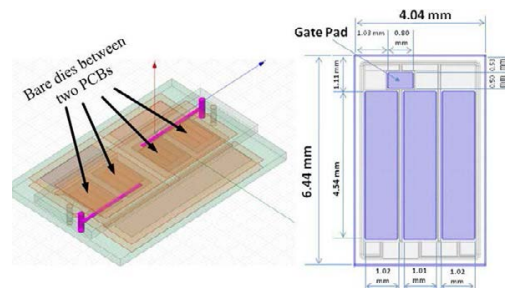

Fig. 3. The layout and the size of the bare die pads (right) and the structure of the planar module with four bare dies from ANSYS Q3D (left).

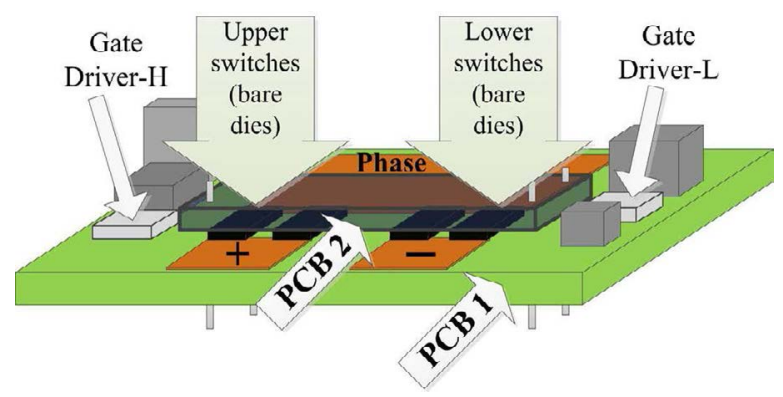

Fig. 4. Structure of the half-bridge planar power module where two bare dies are connected in parallel at each position and can be sandwiched between two substrates.

TABLE I. SimULATION RESULTS SHOWING THE PARASITIC INDUCTANCES OF THE MODULE.

\begin{tabular}{|l|l|l|l|l|}
\hline Parasitic Inductance [nH] & FET 1 & FET 2 & FET 3 & FET 4 \\
\hline GATE & 7.20 & 3.47 & 2.37 & 5.96 \\
\hline DRAIN & 0.0862 & 0.0876 & 0.347 & 0.346 \\
\hline SOURCE & 0.632 & 0.638 & 0.249 & 0.254 \\
\hline
\end{tabular}

TABLE II. SIMULATION RESULTS SHOWS THE PARASITIC resistances OF PCB TRACES

\begin{tabular}{|l|l|l|l|l|}
\hline Parasitic Resistance $[\mu \Omega]$ & FET 1 & FET 2 & FET 3 & FET 4 \\
\hline GATE & 8534 & 4323 & 3131 & 7344 \\
\hline DRAIN & 58.51 & 59.14 & 132.3 & 132.6 \\
\hline SOURCE & 216.5 & 217.1 & 122.4 & 124.2 \\
\hline
\end{tabular}

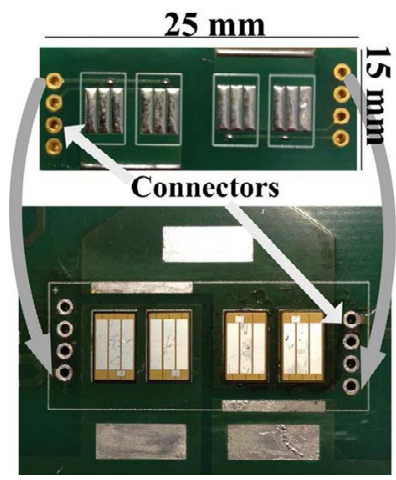

Fig. 5. The figure shows part of PCB 1 (lower) and PCB 2 (upper). SiC MOSFET bare dies are attached to PCB 1. Later, they were sandwiched between PCB 1 and PCB 2 and soldered to PCB 2, forming a planar module. The connector pins were used to transfer the Gate and Source signals. 
The low parasitic inductances, as seen in Table I, enable fast switching speed. Since, FR4 has a relatively large thermal resistance it would not be able to extract any significant amount of heat from the chips. In order to generate the lowest possible heat power a regular DPT-setup was configured, see Fig. 6 . The low-side MOSFETs act as freewheeling path where the current passes through their channels while the high-side MOSFETs were the devices under test (DUT). The first applied pulse was $6 \mu$ s and the second one was $2.5 \mu$ s long. Two identical isolated gate drivers were employed to drive the MOSFETs with an external $\operatorname{Rg}=10 \Omega$ and the gate voltages varied between -3 and $+15 \mathrm{~V}$. An inductor $(30 \mu \mathrm{H})$ was connected in parallel to the low-side switches and the applied voltage was increased stepwise and at $400 \mathrm{~V}$ a current of $75 \mathrm{~A}$ was flowing through the switches. The components used in the planar module are listed in Table III and measurement results are presented in Fig. 7 and Fig. 8. As seen in these figures, there is one overshoot in $\mathrm{V}_{\mathrm{DS}}$ reaching just above $500 \mathrm{~V}$ and no significant oscillations during the turn-off instant can be observed. The rise time of $\mathrm{V}_{\mathrm{DS}}$ was measured to approximately $23 \mathrm{~ns}$. During the turn-on, no oscillation can be observed and the turn-on time was measured to approximately $60 \mathrm{~ns}$.

TABLE III. THE MODULE COMPONENT LIST.

\begin{tabular}{|l|l|l|}
\hline Component & Part number & Function/Remarks \\
\hline Regular PCB & - & $\begin{array}{l}2 \mathrm{~mm} \text { thick FR4 \& 35 } \mu \mathrm{m} \\
\text { copper }\end{array}$ \\
\hline Bare die & CPM2-1200-0025B & Switches \\
\hline DSP & TMDSCNCD28335 & Signal generator \\
\hline $\begin{array}{l}\text { Gate driver } \\
\text { and isolator }\end{array}$ & ADuM3221 & - \\
\hline $\begin{array}{l}\text { DC-DC } \\
\text { converter }\end{array}$ & $\begin{array}{l}\text { Traco TMR 6-2413 and } \\
\text { Capacitor }\end{array}$ GRM188C81E475KE11D & Supply gate-drive circuits \\
\hline Capacitor & CapTacitor bank \\
\hline & Core ETD59 & $\begin{array}{l}\text { The air gap and windings } \\
\text { were changed during the } \\
\text { experiment to adjust the } \\
\text { current }\end{array}$ \\
\hline
\end{tabular}

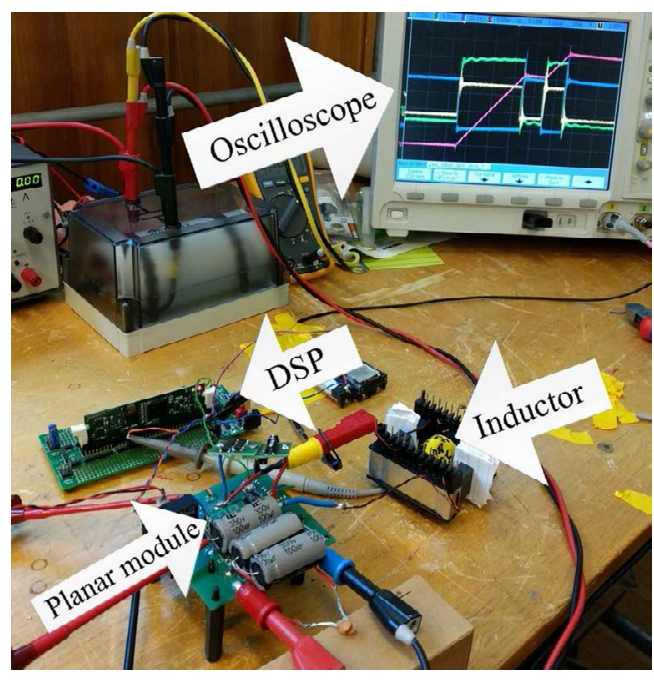

Fig. 6. The figure shows the planar module and the test setup. The gate signals were generated by a digital signal processor (DSP) and were sent directly to two separate digital isolators also acting as gate drivers. The gate signals, $\mathrm{V}_{\mathrm{DS}}$ and inductor current were measured and studied on the oscilloscope.

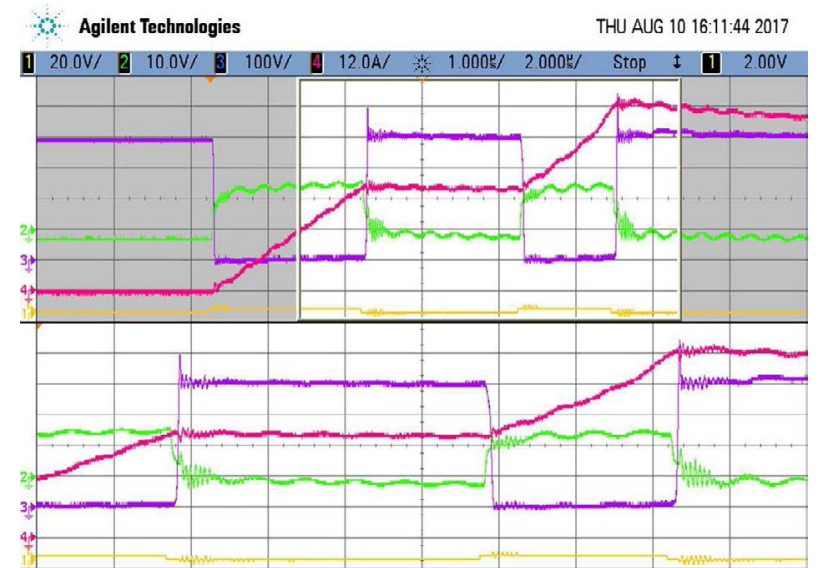

Fig. 7. Measurement results from the DPT. The green pulse shows the gate signal and the lilac shows the $\mathrm{V}_{\mathrm{DS}}$ of the DUT. The red signal is the inductor current and the yellow one shows the control signal from the controller (3.3 V). Time base for the lower graph is $1 \mu \mathrm{s} / \mathrm{div}$.

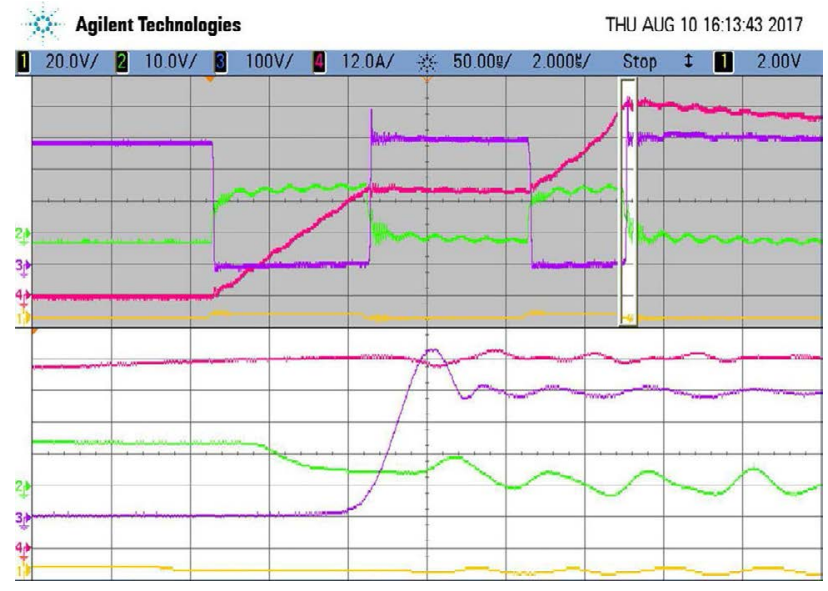

Fig. 8. Measurement results from the DPT. The graph shows the same signals as in Fig. 7. Here the graphs are zoomed into the switching instant when the DUTs turns off. Time base for the lower graph is $50 \mathrm{~ns} /$ div.

In order to measure the signals, an Agilent Technologies (MSO7104A) oscilloscope was used. Voltages were measured by isolated differential probes and the inductor current was measured by a Rogowski Current Transducer (CWT). Since the switch current flows through the copper plate $(35 \mu \mathrm{m} \mathrm{x}$ $10 \mathrm{~mm}$ ) on a $2 \mathrm{~mm}$ PCB, using Rogowski probe would not give an accurate current measurement. Therefore, only the inductor current, and not switch current, was measured during the test, see Fig. 7 and Fig. 8.

\section{Simulations}

Results from the experiment were collected and studied in order to create an accurate model of the structure in the simulation software LT-Spice. The parasitic components from Table I and the model of the switches, provided by Wolfspeed, were integrated into LT-Spice. 


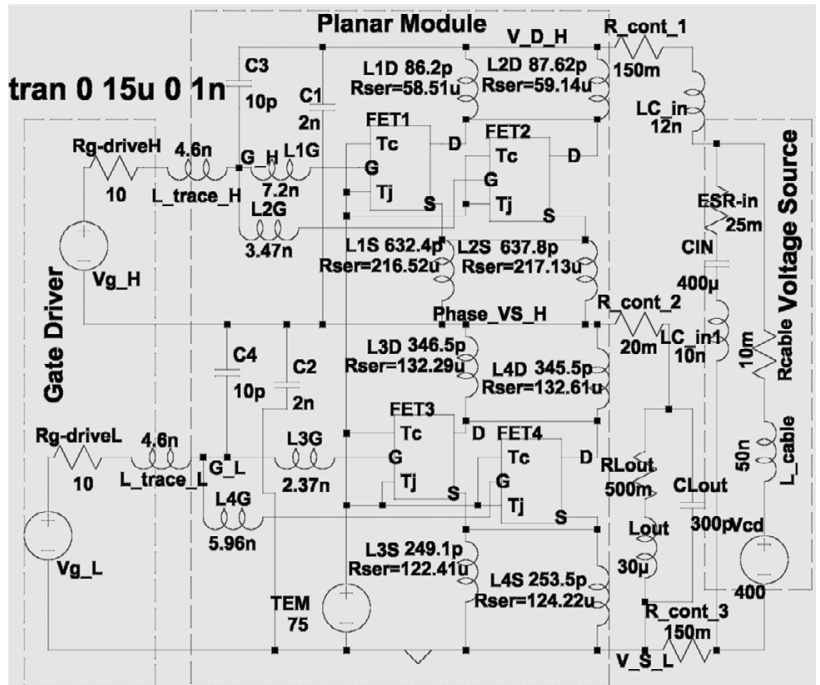

Fig. 9. Schematic diagram of the model of the planar module with two $\mathrm{SiC}$ MOSFETs at each position and the parasitic elements from ANSYS Q3D. The model was used for simulations in LT-Spice. In order to resemble the behavior of the real circuit, additional parasitic components were added into this model.
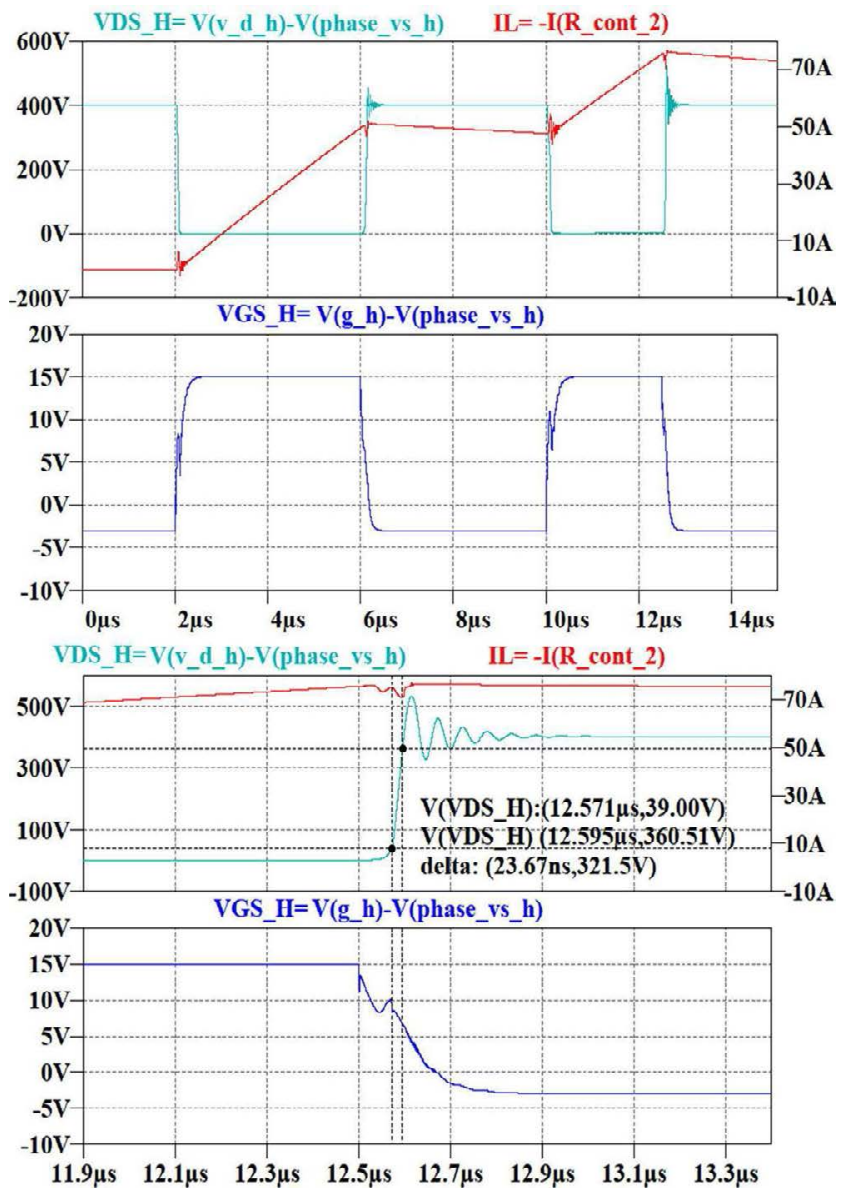

Fig. 10. The figure shows the simulation results from LT-Spice. The inductor current is shown in red, $\mathrm{V}_{\mathrm{DS}}$ of the DUT in turquoise and VGS in blue. The simulation resembles the measurement results.

The developed model of the manufactured planar power module in LT-Spice can be seen in Fig. 9. Additional parasitic elements, for instance capacitances which were excluded in ANSYS Q3D, were added into this model in order to match the simulation and experimental results. The capacitances C1-C4 are produced because of the two parallel PCBs close to each other. The values of these capacitances are adjusted to resemble the measurement results. Also other parasitic elements like $L \_$trace_H, $L \_$trace $L$ and $R \_$cont_ $l$ etc. were estimated and added into the model. Simulation results based on the developed model can be found in Fig. 10. When adjusting the parasitic components, the focus has been on the fall- and rise times, the amplitude of the overshoot and the frequency of the oscillations of $\mathrm{V}_{\mathrm{DS}}$ as well as the inductor current level and waveform.

\section{PROPOSED AND EXPANDED MODEL OF THE PLANAR POWER MODULE}

The obtained model in Fig. 9 represents the manufactured planar power module in Figs. 6 and 5, verified by experiments and simulations. Since the total inductance of a copper trace decreases by increased width, a module with additional number of bare dies connected in parallel may be designed. By using additional bare dies, the width of traces will increase and as result, a lower Drain-to-Source parasitic inductance as well as higher current capability will be obtained. Therefore, the model in Fig. 9 was expanded with two additional bare dies (totally four bare dies in parallel at each position). The new module with four bare dies would manage $1.2 \mathrm{kV} \& 400$ A. A sketch of the proposed expanded module can be seen in Fig. 11. In real applications, the substrates of the proposed module must have a low thermal resistance to conduct the generated heat to the heat sink. For this purpose advanced ceramic material and heat sinks on both sides (double-sided cooling) may be used. In this structure, the same gate signal goes to the up-side (or low-side) MOSFETs through one and the same trace. Therefore, in the model it is assumed that the inductance of the gate trace increases by the previous value plus 1.2 times (worst case) the initial value, which is 3.47 and $2.37 \mathrm{nH}$ for the upper and lower positions, respectively.

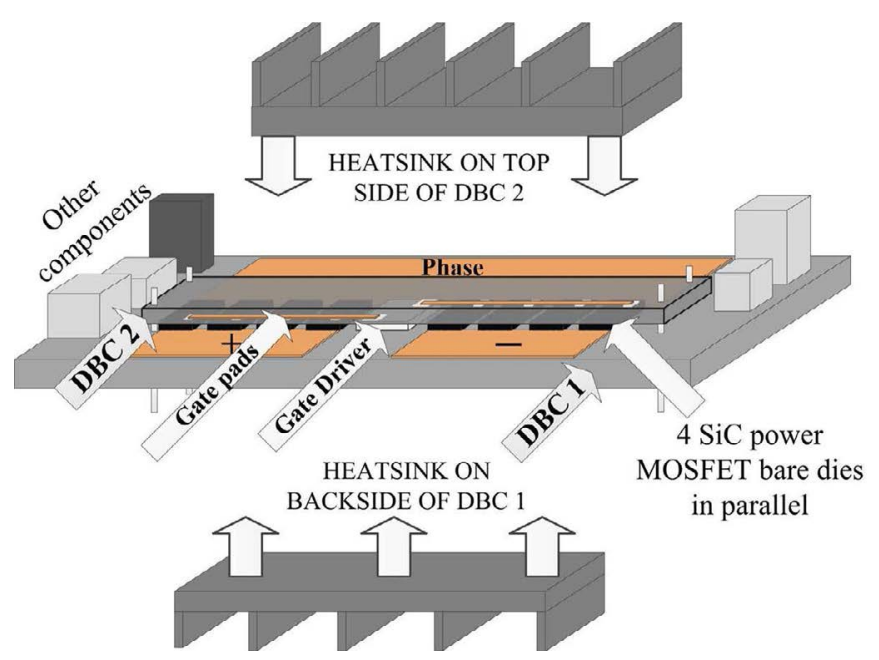

Fig. 11. The proposed structure of the power planar module with four parallel SiC MOSFETs at each position. Unlike regular power modules, the proposed planar module can be cooled from both sides. 
The schematic diagram of the proposed module including the parasitic elements used in LT-Spice is presented in Fig. 12. In this model the values of the parasitic capacitances, caused by the traces, were increased since the area of traces is increased twofold compared to the previous design. Other parasitic elements were kept fixed as in the design with two MOSFETs. The model of the proposed extended module was then simulated in LT-Spice and the results are presented in Fig. 13 and Fig. 14.

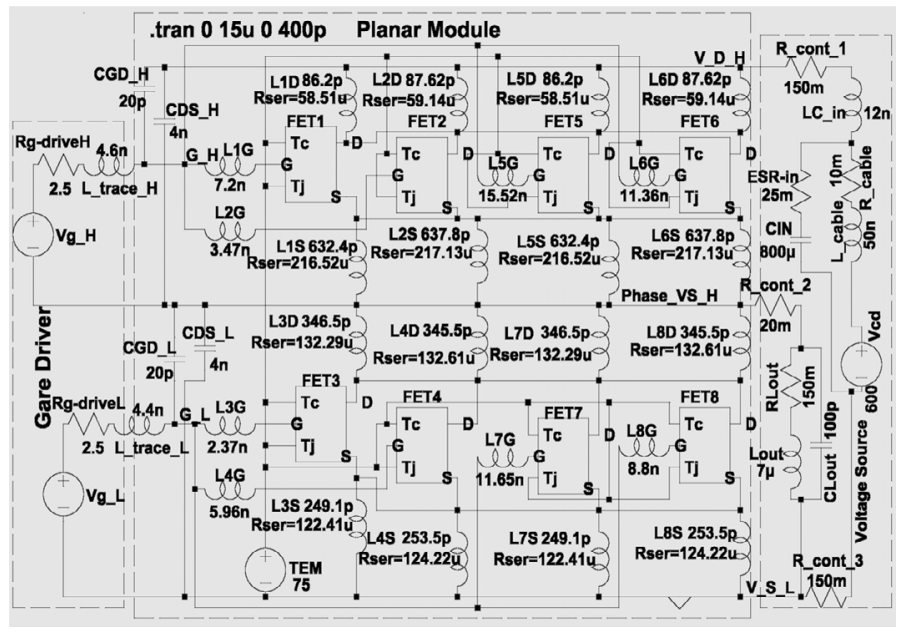

Fig. 12. Schematic diagram of the expanded model of the planar module in Fig. 9 with four SiC MOSFETs bare dies (CPM2-1200-0025B) at each position. This model was used for simulation in LT-spice in order to determine the behavior of the expanded module at $\mathrm{V}_{\mathrm{DS}}=600 \mathrm{~V}$ and $\mathrm{I}_{\mathrm{D}}=400 \mathrm{~A}$.

\section{RESULTS}

The simulation was based on the DPT with the same pulse length as used in the experiment. The value of the inductance was adjusted to $7 \mu \mathrm{H}$ to increase the switch current to approximately $400 \mathrm{~A}(100 \mathrm{~A} / \mathrm{switch})$. Figure 13 shows the gate signals of the upper and lower switches, $\mathrm{V}_{\mathrm{DS}}$, and the current as well as the power losses of the upper switches during the entire simulation time $(15 \mu \mathrm{s})$. Figure 14 shows the same signals zoomed into the switching instants. As seen in these figures the proposed module shows extremely good properties with fast switching times (17.2 and $40.7 \mathrm{~ns}$ ), and very low oscillations in voltage with an overshoot to approx. $850 \mathrm{~V}$, which is $250 \mathrm{~V}$ over the input voltage.

In order to be able to compare the results with commercial modules an external resistance $\mathrm{Rg}=2.5 \Omega$ was used in the simulation. However, by adding a larger gate resistance and decreasing the switching speed, the overshoot and oscillations in $\mathrm{V}_{\mathrm{DS}}$ will reduce. Turn-on $\left(\mathrm{E}_{\mathrm{ON}}\right)$ and turn-off $\left(\mathrm{E}_{\mathrm{OFF}}\right)$ energies were, according to IEC 60747-8-4, calculated to approximately 3.1 and $1.3 \mathrm{~mJ}$ respectively. Most commercial half-bridge modules with $1.2 \mathrm{kV}$ blocking voltage and $400 \mathrm{~A}$ current capability have switching energy losses of approximately 11-13 mJ. In other words, the proposed power module has approximately $63 \%$ lower switching losses at $600 \mathrm{~V} \& 400 \mathrm{~A}$ than for instance CAS300M12BM2 from Wolfspeed.

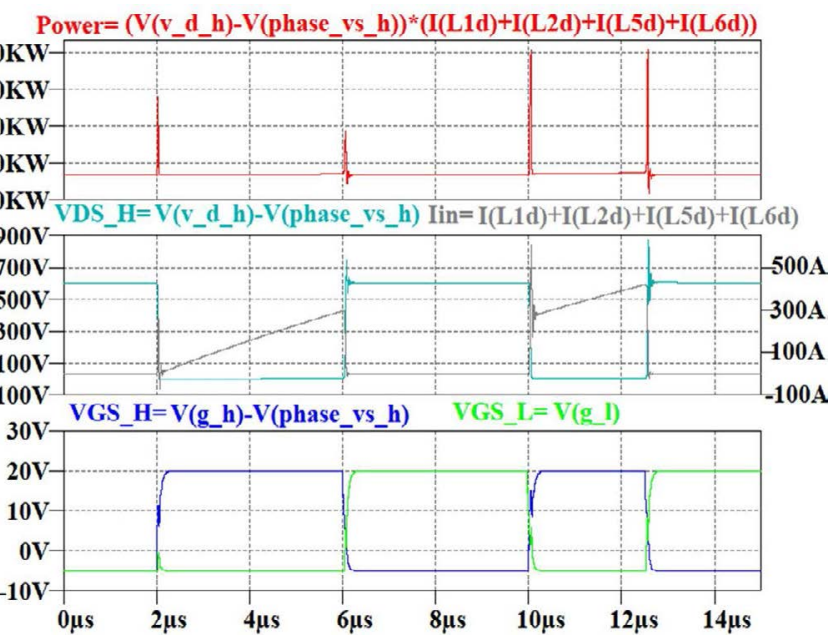

Fig. 13. Simulation result of the proposed planar power module. The total switch current is shown in gray, $\mathrm{V}_{\mathrm{DS}}$ in turquoise, VGS of the upper switches in blue and VGS of the lower switches in green. The instantaneous power is shown in red.
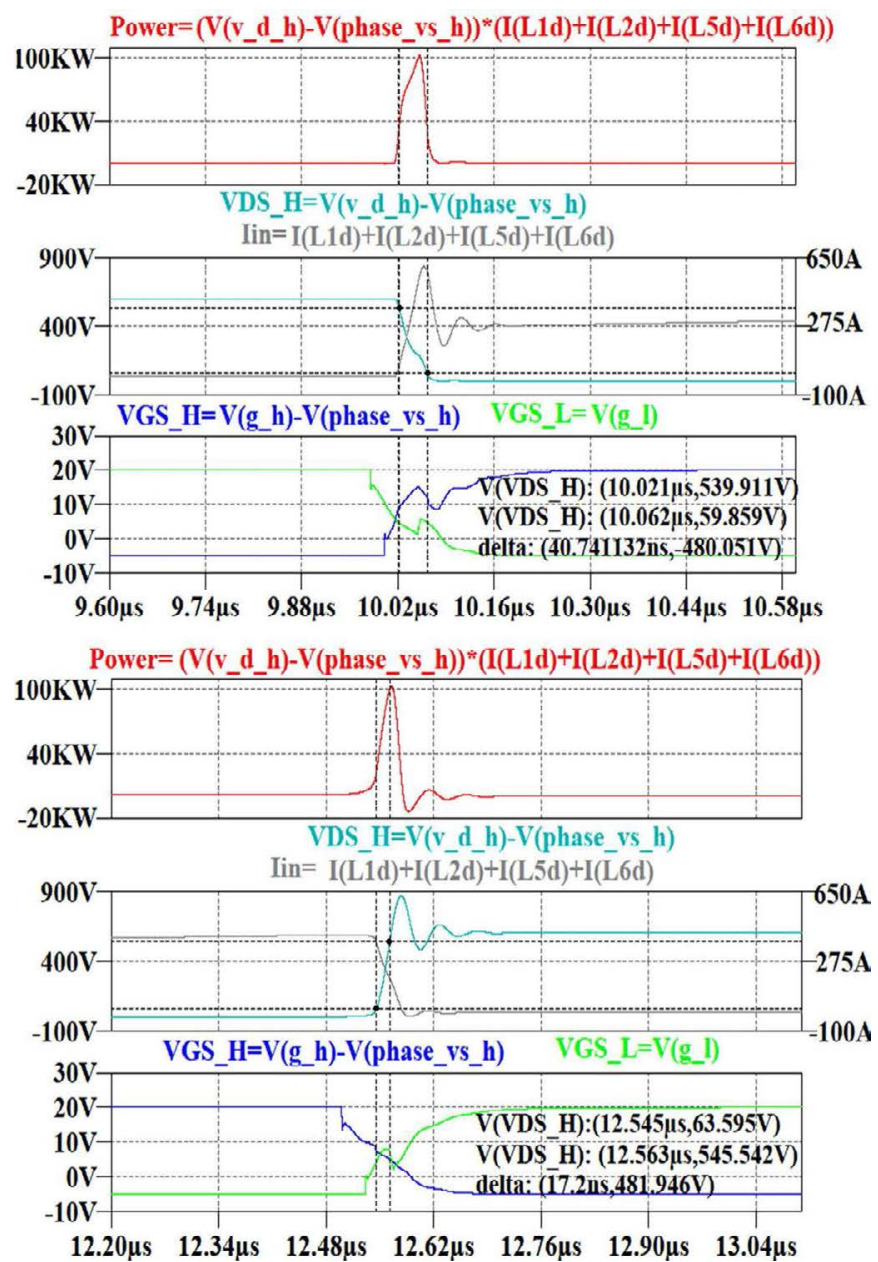

Fig. 14. Simulation result of the proposed planar power module. The total switch current is shown in gray, $\mathrm{V}_{\mathrm{DS}}$ in turquoise, VGS of the upper switches in blue and VGS of the lower switches in green. The instantaneous power is shown in red. The turn-on and turn-off times are $40.7 \mathrm{~ns}$ and $17.2 \mathrm{~ns}$, respectively. 
The result from this study is summarized in Table IV where a selection of parameters of the proposed module was compared to a commercial module. It is assumed that $1 \mathrm{~mm}$ thickness ceramic substrate is used for the proposed module in this comparison. The lower switching losses and the possibility of double-sided cooling in the proposed module will result in lower operating temperature, extended life time of the module and increased power density.

TABLE IV. THE TABLE LISTS AND COMPARES SOME IMPORTANT PARAMETERS BETWEEN THE PROPOSED MODULE AND A COMMERCIAL HALF-BRIDGE MODULE FROM WOLFSPEED.

\begin{tabular}{|l|c|c|}
\hline Module/Parameters & CAS300M12BM2 & $\begin{array}{c}\text { Proposed planar } \\
\text { module }(\mathbf{D B C})\end{array}$ \\
\hline Dimensions $[\mathrm{mm}]$ & $106 \times 62 \times 30$ & $\approx 40 \times 40 \times 3$ \\
\hline Volume $\left[\mathrm{cm}^{3}\right]$ & 197 & $\approx 4.8$ \\
\hline Weight $[\mathrm{g}]$ & 300 & $\approx 20$ \\
\hline $\mathbf{V}_{\text {DS }[\mathrm{kV}]}$ & 1.2 & 1.2 \\
\hline $\mathbf{I}_{\mathbf{D}} @ 25^{\circ} \mathrm{C}[\mathrm{A}]$ & 423 & 400 \\
\hline $\mathbf{R}_{\mathbf{d s}(\text { on) }}[\mathrm{m} \Omega]$ & 4.2 & 6.25 \\
\hline Stray inductance $[\mathrm{mH}]$ & 15 & 0.33 \\
\hline Rise time $[\mathrm{ns}]$ & 68 & 40 \\
\hline Fall time $[\mathrm{ns}]$ & 43 & 17 \\
\hline Double-sided cooling & No & Yes \\
\hline
\end{tabular}

\section{CONCLUSION}

A half-bridge planar power module with two $\mathrm{SiC}$ MOSFET bare dies, with very low parasitic inductances was designed, built and tested. The module was exposed to a double-pulse test and at $400 \mathrm{~V} \& 75 \mathrm{~A}$, the rise and fall times were measured to 23 and $60 \mathrm{~ns}$, respectively. Later on, an accurate simulation model of the module was developed and it was adjusted to resemble the experimental results. The model was then expanded with two additional MOSFETs at each positions for higher current capacity. Simulation results showed that the proposed module has approximately $63 \%$ lower switching energy losses than most commercial modules. From the simulation results, $\mathrm{E}_{\mathrm{ON}}$ and $\mathrm{E}_{\mathrm{OFF}}$ were measured to 3.1 and $1.3 \mathrm{~mJ}$, respectively. An overshoot and some minor oscillations were observed in $\mathrm{V}_{\mathrm{DS}}$ and $\mathrm{I}_{\mathrm{D}}$ in the double-pulse simulations at $600 \mathrm{~V}$ and $400 \mathrm{~A}$. A possible reason for the oscillations is the increased parasitic capacitances in this structure compared to the structure with only two bare dies at each position. The Gate-Drain parasitic capacitance in this structure may have a similar effect as the Miller capacitance. It should be noted that in real applications the distance between substrate 1 and 2 has to be filled in order to handle the electric fields and improve the mechanical and thermal properties. However, the filler material will probably increase the parasitic capacitances, which especially may cause issues if it appears between Gate and Drain of the MOSFETs. A solution to this problem may be to employ a multilayer substrate where the gate trace is placed inside substrate 2 in order to increase the distance between the Gate and Drain traces.

\section{REFERENCES}

[1] S. Hazra, A. De, L. Cheng, J. Palmour, M. Schupbach, B. A. Hull, S. Allen, and S. Bhattacharya, "High switching performance of $1700-\mathrm{V}$, 50-A SiC power MOSFET over Si IGBT/BiMOSFET for advanced power conversion applications," IEEE Trans. Power Electron., vol. 31, no. 7, pp. 4742-4754, Jul. 2016.

[2] Q. J. Zhang, G. Wang, C. Jonas, C. Capell, S. Pickle, P. Butler, D. Lichtenwalner, E. V. Brunt, S. Ryu, J. Richmond, B. Hull, J. Casady, S. Allen, and J. Palmour, "Next generation planar 1700 V, 20 mohm; $4 \mathrm{H}-\mathrm{SiC}$ DMOSFETs with low specific on-resistance and high switching speed," in European Conference on Silicon Carbide Related Materials (ECSCRM), Sep. 2016, pp. 1-1.

[3] H. Sato, F. Kato, H. Nakagawa, H. Yamaguchi, S. Rejeki, and F. Lang, "Development of SiC power module for high-speed switching operation," in IEEE Electrical Design of Advanced Packaging Systems Symposium (EDAPS), Dec. 2013, pp. 13-16.

[4] E. Velander, L. Kruse, and H. P. Nee, "Optimal switching of SiC lateral MOSFETs," in 17th European Conference on Power Electronics and Applications (EPE'15 ECCE-Europe), Sep. 2015, pp. 1-10.

[5] E. Velander, L. Kruse, T. Wiik, A. Wiberg, J. Colmenares, and H. P. Nee, "An IGBT turn-on concept offering low losses under motor drive $\mathrm{dv} / \mathrm{dt}$ constraints based on diode current adaption," IEEE Trans. Power Electron., vol. PP, no. 99, pp. 1-1, Feb. 2017.

[6] P. Nayak and K. Hatua, "Parasitic inductance and capacitance-assisted active gate driving technique to minimize switching loss of $\mathrm{SiC}$ MOSFET," IEEE Trans. Ind. Electron., vol. 64, no. 10, pp. 8288-8298, Oct. 2017.

[7] J. Colmenares, D. Peftitsis, J. Rabkowski, D. P. Sadik, and H. P. Nee, "Dual-function gate driver for a power module with SiC Junction Field-Effect transistors," IEEE Trans. Power Electron., vol. 29, no. 5, pp. 2367-2379, May 2014.

[8] N. Rouger, J. Widiez, L. Benaissa, B. Imbert, P. Gondcharton, B. Letowski, and J. Crebier, "3D packaging for vertical power devices," in CIPS 2014; 8th International Conference on Integrated Power Electronics Systems, Feb. 2014, pp. 1-6.

[9] Z. Liang, F. Wang, and L. Tolbert, "Development of packaging technologies for advanced SiC power modules," in IEEE Workshop on Wide Bandgap Power Devices and Applications, Oct. 2014, pp. 42-47.

[10] Z. Zhang, J. Fu, Y. F. Liu, and P. C. Sen, "Switching loss analysis considering parasitic loop inductance with current source drivers for buck converters," IEEE Trans. Power Electron., vol. 26, no. 7, pp. 1815-1819, Jul. 2011.

[11] T. Meade, D. O'Sullivan, R. Foley, C. Achimescu, M. Egan, and P. McCloskey, "Parasitic inductance effect on switching losses for a high frequency dc-dc converter," in 2008 Twenty-Third Annual IEEE Applied Power Electronics Conference and Exposition, Feb. 2008, pp. 3-9.

[12] T. Yamamoto, K. Hasegawa, M. Ishida, and K. Takao, "Switching simulation of $\mathrm{SiC}$ high-power module with low parasitic inductance," in International Power Electronics Conference (IPEC-Hiroshima - ECCE ASIA), May 2014, pp. 3707-3711.

[13] F. Yang, Z. Liang, Z. J. Wang, and F. Wang, "Design of a low parasitic inductance $\mathrm{SiC}$ power module with double-sided cooling," in IEEE Applied Power Electronics Conference and Exposition (APEC), Mar. 2017, pp. 3057-3062.

[14] Z. Liang, "Integrated double sided cooling packaging of planar SiC power modules," in IEEE Energy Conversion Congress and Exposition (ECCE), Sep. 2015, pp. 4907-4912.

[15] K. Takao and S. Kyogoku, "Ultra low inductance power module for fast switching sic power devices," in IEEE 27th International Symposium on Power Semiconductor Devices IC's (ISPSD), May 2015, pp. 313-316.

[16] A. E. Risseh, H. Nee, and K. Kostov, "Electrical performance of directly attached $\mathrm{SiC}$ power MOSFET bare dies in a half-bridge configuration," in IEEE 3rd International Future Energy Electronics Conference and ECCE Asia (IFEEC 2017 - ECCE Asia), Jun. 2017, pp. 417-421.

[17] A. E. Risseh, H. P. Nee, and K. Kostov, "Realization of a planar power circuit with silicon carbide MOSFETs on printed circuit board," in 24th International Symposium on Power Electronics, Electrical Drives, Automation and Motion - (SPEEDAM 2018), Jun. 2018. 